\title{
Remote Sensing Monitoring of Soil Moisture Content in Xilin River Basin*
}

\author{
Hongbo $\mathrm{Yu}^{1,2}$, Qiaofeng Zhang ${ }^{1,2}$ \\ 1 College of Geograghy Science, Inner Mongolia Normal University, Huhhot 010022, China \\ 2 Inner Mongolian Key Laboratory of Remote Sensing and Geography Information System, Inner \\ Mongolia Normal University, Huhhot 010022, China
}

\section{锡林河流域土壤含水量遥感监测" \\ 于红博 ${ }^{1,2}$, 张巧风 ${ }^{1,2}$ \\ 1 内蒙古师范大学地理科学学院, 呼和浩特 010022 , 中国 \\ 2 内蒙古师范大学遥感与地理信息系统重点实验室, 呼和浩特 010022 , 中国}

\begin{abstract}
The study area is the Xilin River basin. Remote sensing approach was used to retrieve soil moisture content based on the surface water capacity index by using MODIS images from July 2000 to July 2012. This can reflect the scope, extent and development of the drought in the study area in a timely and accurate manner. It is of great significance to develop scientific and reasonable measures of drought control and drought resistance. The results show that the spatial distribution of soil moisture content is consistent with the surface state. The soil moisture content in the upper reaches is higher than in the middle and lower reaches. In the time distribution, the soil moisture content of fifteen years from 2000 to 2014 is no fixed trend. The trend of soil moisture content is consistent with precipitation.
\end{abstract}

Keywords: Xilin River basin,soil moisture content,remote sensing,SWCI

\section{摘要}

本研究选择锡林河流域为研究区, 基于地表含 水量模型, 利用遥感方法对2000-2014年每年7 月的MODIS 影像数据进行处理, 估算出流域 土壤含水量, 并用实测数据进行修正。这对及

*内蒙古自然科学基金项目 (2013MS0611)
时准确地反映研究区干旱可能发生的范围、程 度和发展变化, 对制定科学合理的防旱、抗旱 措施具有十分重要的意义。结果表明, 反演得 到的土壤含水量分布与地表状况比较吻合, 均 为上游大于中下游；2000年-2014年这 15 年流 域土壤含水量的时间变化没有固定的趋向, 基 本与各年7月份降水量的变化趋势相一致。

关键字: 锡林河流域, 土壤含水量, 遥感, SWCI

中国北方草原, 降水稀少, 近年来随着工 业经济、城镇化的快速发展, 工业用水增长迅 速, 农业、居民生活和工业用水与生态系统用 水之间的矛盾日益突出。随着全球变暖趋势的 影响, 干旱问题日趋严重。在干旱的遥感监测 中, 由于土壤水分受降水、气温、土壤质地等 多种因子的影响, 且植被覆盖的干扰不容忽 视, 因而土壤含水量的遥感反演是重点和难点 $[1,2]$ 。杜晓从水的波谱反射特性入手, 分析了含 水土壤和植被的共同特征,提出了一种适合于 土壤和植被混合区域的地表含水量指数 (surface water capacity index,SWCI) 模型。

本研究选择锡林河流域为研究区, 运用遥 感方法, 结合气象资料, 对 2000-2014 年每年 7 月份的影像进行处理, 估算该流域的月土壤 含水量, 来初步探究锡林河流域土壤含水量的 时空变化, 这对及时准确地反映研究区干旱可 能发生的范围、程度和发展变化, 对制定科学 合理的防旱、抗旱措施具有十分重要的意义。 
Risk Analysis and Crisis Response in Big Data Era (RAC-16)

\section{1. 研究区概况}

锡林河流域位于内蒙古高原中东部, 它东 缘属于大兴安岭西麓低山丘陵区, 地势由东向 西逐渐降低, 流域总面积约 $10786 \mathrm{~km}^{2}$, 总长 $175 \mathrm{~km}^{[3,4]}$ 。该区的土壤具有明显的地带性, 即 由东南向西北有规律地分布着黑钙土、暗栗钙 土和淡栗钙土。

气候属大陆性温带半干旱气候, 冬季寒冷 干燥, 夏季温暖湿润 ${ }^{[5]}$, 根据多年气象资料, 锡林河内从东南向西北降水量逐渐递减, 东南 部的年降水量为 $400 \mathrm{~mm}$ 左右,西北部为 $250 \mathrm{~mm}$ 左右, 年平均气温则从东南向西北逐 渐增加 ${ }^{[4]}$ 。

锡林河流域地带性植被的基本类型是草 原(草甸草原、典型草原),约占植被总面积的 $85 \%$; 锡林河上游地势较高的三级熔岩台地上, 代表群系为贝加尔针茅(Stipa baicalensis)草原 和线叶菊(Filifoliusibiricum)草原, 中游暗栗钙 土亚带的代表群系为羊草(Leymus chinensis) 草原和大针茅(Stipa grandis)草原,下游淡栗钙 土亚带的代表群系为克氏针茅(Stpa krylovii) 草原和冷蒿(Artemisia frigida)草原 ${ }^{[4,6]}$; 在锡林 河流经区域的地段上形成了湿地植被,此外,在 锡林河流域还有浑善达克沙地东北端榆树疏 林、灌从、草本镶嵌分布所形成的沙生植被 ${ }^{[7]}$ 。

\section{2. 数据来源}

\section{1 气象数据}

由中国气象科学数据共享服务网提供的 2000 年-2014 年每年 6 月 25 日-8 月 12 日逐日 降水数据。包括研究区锡林浩特市及周边阿巴 嘎旗、东乌珠穆沈旗、克什克腾旗、西乌珠穆 沈旗、多伦县、化德共 7 个站点的站点数据。

以上气象数据均利用 Kriging 方法进行了 插值处理。

\section{2 遥感数据}

遥感影像资料为美国 NASA 提供的 2000 年-2014 年每年 6 月 25 日-8 月 12 日锡林河流 域 8 天合成 MODIS 卫星数据地表反射率产品 MOD09A1, 是经过验证、MODIS 科学组推荐 使用的 $\mathrm{L} 3$ 级产品, 版本为 5.0 , 数据分辨率 $500 \mathrm{~m}$ ，投影为 Albers Conical Equal Area。

\section{3 实测数据}

野外实测 $0-0.5 \mathrm{~m}$ 深度土壤含水量数据, 每个样地三次重复, 在研究区内共设有 20 个
样地。

2.4 数据处理软件

用 MRT 软件对 MODIS 影像进行投影转 换, 用 Envi 和 arcGIS 软件对 MODIS 影像进 行处理、运算、分析和制图。

\section{3. 理论及研究方法}

SWCI 能较好地反映地表含水量值, 更适 用于大范围且快速的土壤水遥感监测。杜晓提 出的地表含水量指数 SWCI 为:

$$
S W C I=\frac{b 6-b 7}{b 6+b 7}
$$

式中,b6、b7 分别为 MODIS 数据的第 6、 第 7 波段反射率值。该模型从水的吸收对植被 和土壤反射率波谱的综合影响入手,直接获取 其地表水分含量指标。

计算得到的土壤含水量用野外实测数据 $(0.5 \mathrm{~m}$ 深度内的土壤体积含水量)进行了修正。 同时根据包括该月中日子的遥感结果按所占 日数进行了加权平均得到月土壤含水量。

\section{4. 结果分析}

\section{1 锡林河流域土壤含水量空间分析}

图1为反演得到的2012年7月份月平均土 壤含水量分布图。由于植被类型、自然条件的 差异, 锡林河流域各地区土壤含水量差异较 大。由图可知, 反演得到的土壤含水量分布与 地表状况比较吻合，与植被覆盖区域基本一 致, 锡林河流域走势为东南一一西北, 大部分 地区为典型草原区，上游有小部分区域为草甸

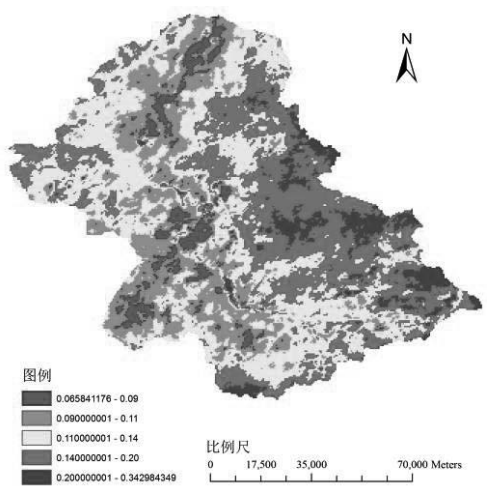

图 12012 年 7 月锡林河流域 MODIS 影像反 演的月平均土壤含水量

草原区; 该流域的土壤具有明显的地带性, 即 


\section{Risk Analysis and Crisis Response in Big Data Era (RAC-16)}

由东南向西北有规律地分布着黑钙土、暗栗钲 土和淡栗钙土; 根据多年气象资料, 锡林河内 从东南向西北降水量逐渐递减。受植被、气候、 土壤等条件的影响, 上游地区土壤含水量高于 中下游地区。河流及两侧的低湿地植被、上游 地区的草甸草原土壤含水量较大。

4.2 锡林河流域土壤含水量空间变化分析

为便于分析2000年-2014年锡林河流域土 壤含水量的变化, 采用了统一的分类阈值, 制 作了 2000 年-2014年每年7月锡林河流域月平 均土壤含水量分布图, 如图2所示。由图可知,
在空间分布上, 基本均为土壤含水量上游大于 中游, 中游大于下游, 与该流域植被类型、自 然条件相一致。由于土壤水分主要为降水补 给, 因此, 降水量大的年份, 土壤含水量大, 土壤含水量大的区域所占面积越大, 包括流域 大部分区域(如2012年), 降水量小的年份, 土 壤含水量也小, 土壤含水量大的区域仅出现在 上游地区及河流流经地段(主要是低湿地植 被, 如2000年)。
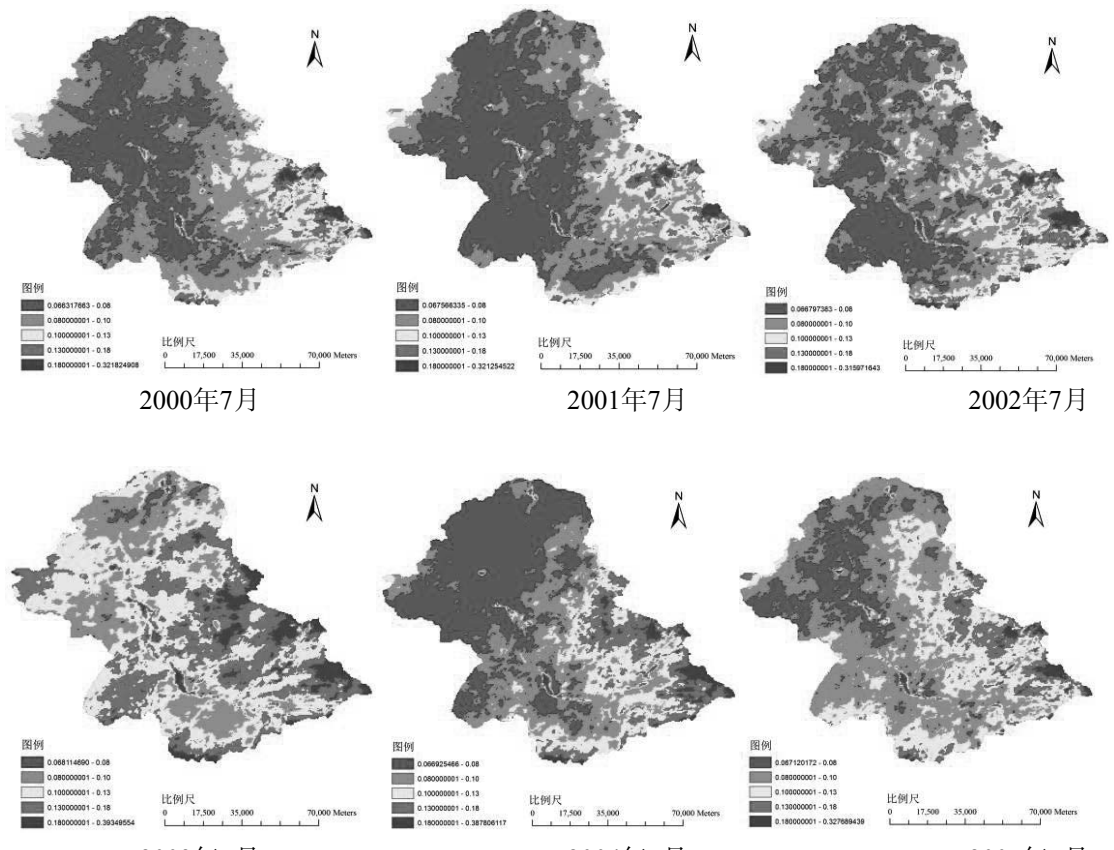

2003年7月
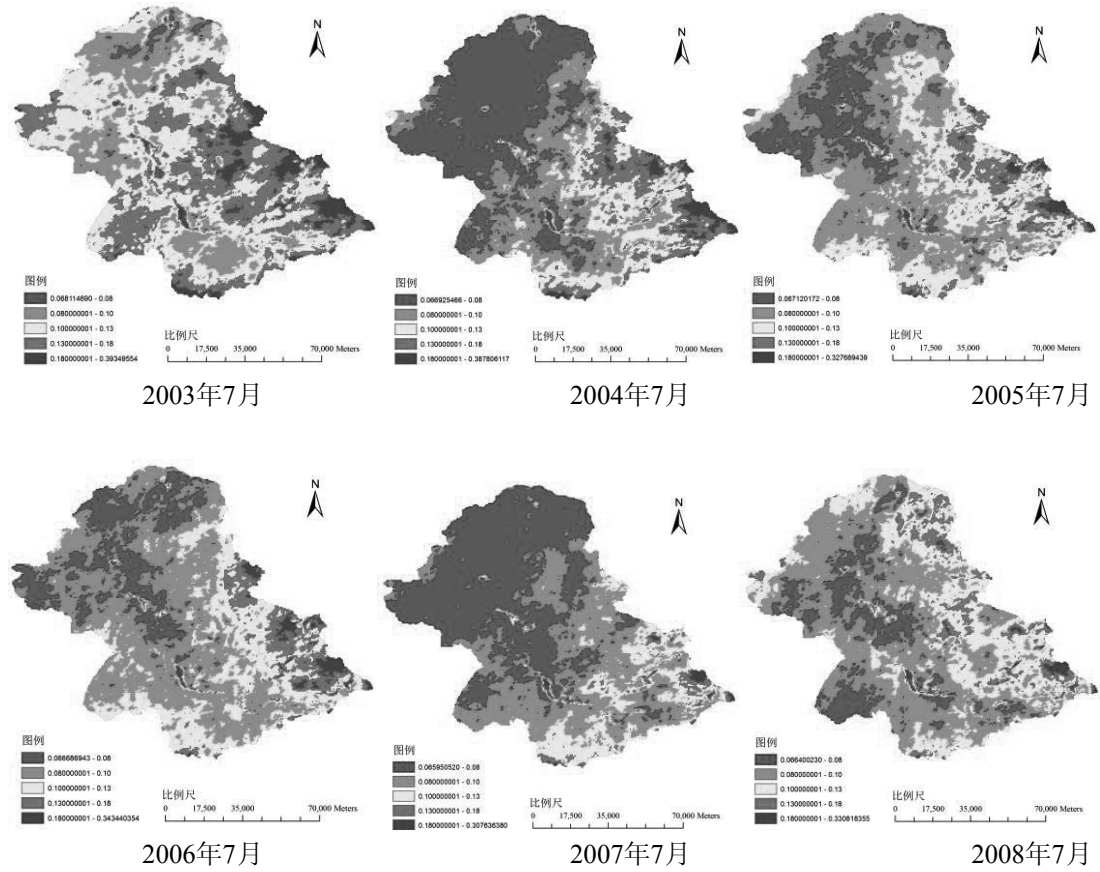
Risk Analysis and Crisis Response in Big Data Era (RAC-16)

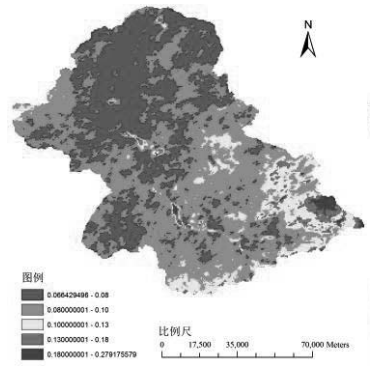

2009年7月

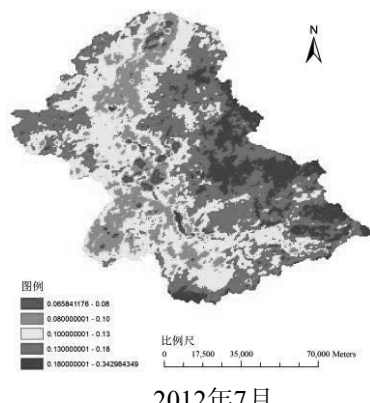

2012年7月

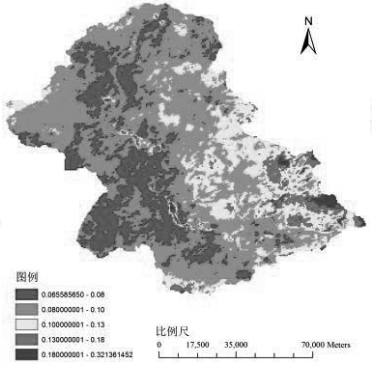

2010年7月

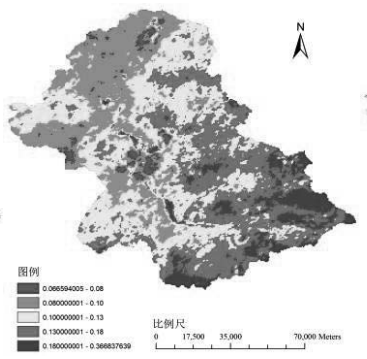

2013年7月

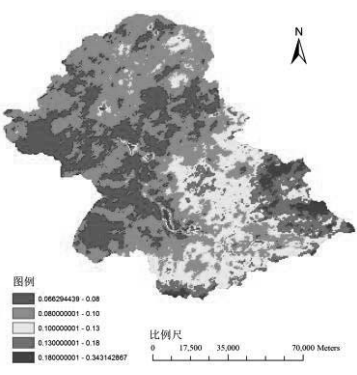

2011年7月

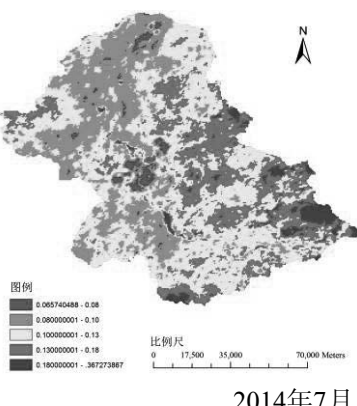

2014年7月

图例

$\min -0.08$ $0.080000001-0.10$ $0.100000001-0.13$

$0.130000001-0.18$

$0.180000001-\max$

图2 2000年-2014年每年7月锡林河流域月平均土壤含水量

4.3 锡林河流域土壤含水量时间变化分析

图 3 为反演的锡林河流域 2000 年-2014 年每年 7 月份土壤含水量变化曲线图, 由图可 知, 土壤含水量的时间变化没有固定的趋向,
土壤含水量最大值出现在 2012 年，土壤含水 量最小值为 2007 年, 基本与各年 7 月份降水 量的趋势相一致, 与同期降水量的相关系数为 0.747 , 降水量为影响土壤含水量的主要因子。

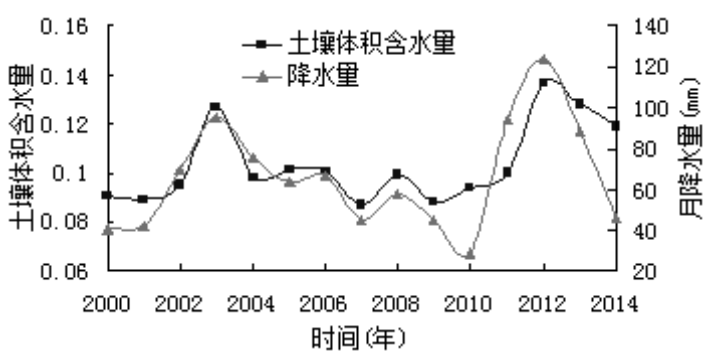

图 3 锡林河流域 2000 年 7 月-2014 年 7 月份月土壤含水量与月降水量年际变化

\section{5. 结论}

本研究选择锡林河流域为研究区, 基于 SWCI 指数, 运用遥感方法, 对 MODIS 影像 进行处理及运算, 反演出 2000-2014 年每年 7
月份土壤含水量值, 并用实测数据进行了修 正。

反演得到的土壤含水量分布与地表状况 比较吻合, 与植被覆盖区域以及土壤的地带性 
Risk Analysis and Crisis Response in Big Data Era (RAC-16)

分布相一致, 各个年份土壤含水量均为上游大 于中下游, 降水量大的年份, 土壤含水量大, 土壤含水量大的区域所占面积越大, 包括流域 大部分区域, 反之亦然。

2000年-2014年这15年流域土壤含水量的时间 变化没有固定的趋向, 基本与各年7月份降水 量的趋势相一致, 降水量为影响土壤含水量的 主要因子。

\section{参考文献}

[1] 杜晓, 王世新, 周艺, 魏华.一种新的基于 MODIS 的地表含水量模型构造与验证.武 汉大学学报 (信息科学版). 2007, 32(3):205-207,211.

[2] C.Y. Song, R. Zhang, A.X. Zhou, M. Hong. Water security risk assessment of the yellow river basin on constrained-random weight and cloud model. Journal of Risk Analysis and Crisis Response, 2013, 3(4): 201-209.

[3] 全川, 杨景荣, 雍伟义 等.锡林河流域草
原植被退化空间格局分析. 自然资源学 报.2002.17(5): 571-578.

[4] 白永飞, 张丽霞, 张炎 等.内蒙古锡林河 流域草原群落植物功能群组成沿水热梯 度变化的样带研究. 植物生态学 报.2002.26(3):308-316.

[5] 肖向明, 王义凤, 陈佐忠.内蒙古锡林河流 域典型草原初级生产力和土壤有机质的 动态及其对气候变化的反应. 植物学 报.1996.38(1): 45-52.

[6] 顾晓鹤, 何春阳, 潘耀忠 等.基于生态风 险评估的锡林河流域退化草地优化管理. 应用生态学报.2007.18(5): 968-976.

[7] 刘佳慧, 刘芳, 王炜 等.“3S”技术在生态 用水量研究中的应用——以锡林河流域 为例. 干旱区资源与环境.2005.19(4): 92-97. 